The Report of the Meeting of the British Association for the Advancement of Science

IT would be a great boon to the English public if the papers which are read before the members of the Association, or rather those who have the means as well as the inclination to attend such important annual gatherings, could be published within the first few weeks immediately after the meeting, and at such a price as many in this land would by no means grudge. According to the present arrangement, some months have to pass before even such as can afford the heavy price placed upon these reports can obtain them, the result of which is, that the poor and meagre reports of the various newspapers are all that the majority of persons have to inform them about the advancement of science. Could not some such report as that authorised by the committee of the Churcil Congress be produced? The first Congress was reported fully, the papers entire, and the discussions almost so, in a well-printed volume of nearly 500 pages, for the moderate sum of half-a-crown, prepaid; or four shillings if purchased atterwards. There are many, I am convinced, who would gladly prepay three or even four half-crowns for the report of the papers only which are read before the British Association.

Birkenhead

G. H. H.

\section{TERRESTRIAL MAGNETISM}

$\mathrm{T}$

$\mathrm{E}$ great progress made during the last few years in our knowledge of the phenomena of terrestrial magnetism has naturally attracted not a little attention to this interesting subject, and the persevering efforts of many leading scientific men are the surest guarantee of the ultimate success of the labours undertaken in this cause. Hitherto theory has gone hand in hand with observation, and those most able to undertake the charge are now only waiting a more complete array of facts, in order to present us with a theory of terrestrial magnetism based on solid foundations, and equal in interest, in completeness, and in the utility of its practical applications, to any of its sister sciences. The required facts may be ranged under these two heads. First the actual values of the magnetic elements at all parts of the earth's surface, with the secular variations of these elements; and secondly, the daily, monthly, and yearly range through which these quantities vary, and the irregular perturbations to which they are subject. To meet the first demand, a complete set of magnetic observations must be taken in different countries, the stations of observation not being too far distant from each other ; and a repetition of these at intervals of from ten to twenty years will supply an accurate record of the secular variations of the required elements. The second need can only be satisfactorily provided for by the establishment of permanent magnetic observatories, supplied with self-registering magnetographs, by which every change of the magnetic force can be correctly traced.

Fortunately much has already been effected, and more is actually being carried out for the furtherance of this latter object. This country alone possesses three such observatories, Lisbon another, Florence a fifth, and four others are at present in course of erection, at St. Petersburg, Bombay, Melbourne, and the Mauritius. The fact, now clearly established, that any disturbance of the magnetic needle traced by our magnetographs in England has a corresponding perturbation recorded at Lisbon and at Florence, is an earnest of what we may expect from a careful comparison of magnetograms from all quarters of the globe.

But the other branch of observation, on which the determination of the absolute values of the magnetic elements solely depends, has scarce kept pace with the giant strides of the fixed observatories. Doubtless a series of monthly absolute readings is being taken at each magnetic observatory to serve as a basis for the differential curves traced by the magnetographs; but such observatories will always be few in number, and the accuratc determination of the magnetic elements of these few points, however useful it may be, will scarcely suffice to give us a complete knowledge of the magnetic condition of the earth's surface. The survey of the ocean we may well trust to the devoted and persevering enterprise of the naval officers, who are adding so much to our store of meteorological and magnetic knowledge; but for the land surveys we must mainly depend on the accurate observations of private observers. A very limited number of scattered observations made at stations remote from each other, and the careful survey of scarcely half a dozen countries of Europe, is all we can point to as at present accomplished. If it be true that labour and expense are the great obstacles to be overcome when an important enterprise has to be undertaken, we may well wonder that the more laborious and by far the most expensive of the observations needed for the science of terrestrial magnetism are being amply supplied by the establishment of fixed observatories, whilst the magnetic surveys, which may be now made an agreeable pastime, and need scarcely add perceptibly to our usual expenses, are nearly entirely neglected. Most men who are daily engaged in intellectual occupations, require yearly a few weeks of repose, or at least of mitigated application. For many, some interesting work that does not too much engross their minds, and that differs considerably from their usual routine duties, offers a means of relaxation far more enticing than a complete cessation from labour. For men of this class, who have had some little experience in the use of instruments of precision, a magnetic survey might offer the greatest attraction during a summer vacation. A brief sketch of a simple method of carrying this into effect, which has been found to work well during two successive vacations, may not therefore be without its utility and interest.

The country chosen for a rapid survey should be one that offers considerable facilities for railway communication ; and a previous study of the direction of the lines will prevent much unnecessary expense and loss of time from travelling twice over the same ground. Should the railway arrangements of the country resemble those of France, a companion for the journey becomes an absolute necessity; for the instruments used are of too delicate a make to be entrusted to the tender mercies of foreign railway officials of the registered baggage department.

The instruments required for the survey are a dip circle, an unifilar, a small transit theodolite, and a good chronometer. Two tripod stands are neariy a necessity if time be any consideration. Three days might conveniently be allotted to each station; one for travelling, another for the observations, and the third for visiting the objects of interest in the vicinity. Twenty sets of observations would thus be completed in the course of two months; and two vacations so employed would furnish data sufficient for the accurate study of the magnetic condition of an extensive tract of country. But should the time at the observer's disposal be more limited, and he feel equal to the task, the day of travelling might reckon as a day of rest, and the public monuments be visited during the leisure hours of the day of observation.

Arrived at a station, the first thought should be about the choice of a fit place of observation. The garden of any large public institution will perhaps in general be found the most convenient and accessible, unless an extensive and somewhat retired garden be attached to the hotel. Inquiry must next be made about the position of any considerable mass of iron, such as large pipes, which serve not unfrequently to convey gas or water at a few feet below the surface of a gravel walk or a grass plot. For the observation of the dip and the intensity, a good shady spot is required; whilst, for the declination, a position well exposed to the sun, at the early hours of the morning, is the best possible. A tent may sometimes be required to supply the want of trecs; but whon a large canvas 